\title{
Computed Tomographic Localization of the Central Sulcus: A Morphometric Study in Adult Patients
} \author{
Pablo AJLER ${ }^{2}$ \\ ${ }^{1}$ Instituto Universitario del Hospital Italiano, Buenos Aires, Argentina \\ ${ }^{2}$ Hospital Italiano, Department of Neurosurgery, Buenos Aires, Argentina \\ ${ }^{3}$ University of Pittsburgh Medical Center, Department of Neurosurgery, Pennsylvania, USA
}

Dan ZIMELEWICZ OBERMAN¹, Jorge RASMUSSEN², Maximiliano TOSCANO², Ezequiel GOLDSCHMIDT²,

\section{ABSTRACT}

AIM: To accurately describe the relations between the anatomical landmarks of the cranial convexity and the main cortical structures. MATERIAL and METHODS: A retrospective cross-sectional, observational study was performed. Computed tomography scans of 71 adult patients with no pathological imaging were analyzed. The position of the bregma and the central sulcus was determined. The distances from bregma to the pre-central and post-central sulci were calculated. The relationships from the nasion and glabella to cortical structures were also assessed.

RESULTS: The mean distances between the bregma and the pre-central, central and post-central sulci were $26.8 \pm 7.2 ; 47.8 \pm 5.9$ and $60.6 \pm 5.7 \mathrm{~mm}$, respectively, without gender discrepancy. The mean distance nasion-bregma and the nasion-related measures showed significant differences among sexes.

CONCLUSION: The central sulcus was located accurately, on average $47.8 \mathrm{~mm}$ behind the bregma, which should be used instead of nasion in order to avoid gender discrepancy. The data obtained provide useful and reliable information to guide neurosurgical procedures.

KEYWORDS: Bregma, Central sulcus, Computed tomography, Craniometric points

\section{INTRODUCTION}

$\mathrm{T}$ he surgical treatment of lesions involving the central lobe requires careful planning due to its neurologic eloquence. Superficial skull landmarks become essential when performing cranial surgery because their relationships with underlying cortical regions seem constant enough to be taken into account during surgical planning $(1,2,10)$.

The convexity of the skull lacks evident muscle insertion points or clear marked edges. However, the joint between the skull bones, the cranial sutures, can be recognized intraoperatively in most cases, following neatly periosteal detachment (Figure 1). The usefulness of this skull-brain relationship has been described both in cases of conventional craniotomy (1), or in single burr hole procedures, like placing of intracranial pressure (ICP) monitoring devices or external ventricular drains (EVD) (2), and ventricular neuroendoscopy.

In an era of image-guided neurosurgery, craniometric points may seem to be out of date; nevertheless, anatomical knowledge cannot be replaced by any guidance instrument. Indeed, the craniometric relationships can be used as "internal control" to the application of advanced guidance techniques (neuronavigation, neurophysiological monitoring, etc). In emergency cases such as trauma, neuronavigation can be out of reach. Three-dimensional understanding and "x-ray vision" reasoning establish elemental tools to safe surgical planning and execution. 


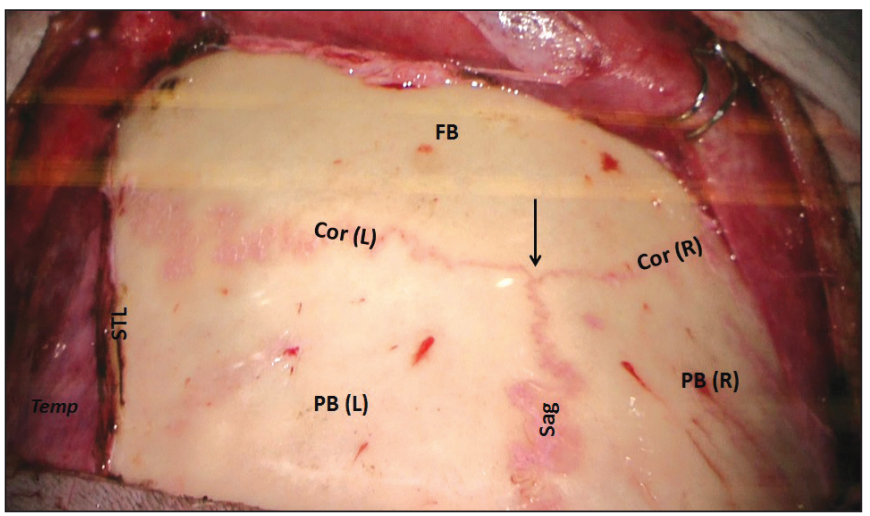

Figure 1: Intraoperative, superior view. The intersection between coronal (Cor) and sagittal (Sag) sutures, bregma, is pointed (black arrow). FB, frontal bone; PB, parietal bone; STL, superior temporal line; temp, temporal muscle; $\mathbf{L}$, left; $\mathbf{R}$, right.

Our aim was to accurately describe the position of classic skull landmarks and its relations with the central lobe structures, but unlike the previous reports, to measure them on a wide quantity of samples by tomographic data.

\section{MATERIAL and METHODS}

\section{Patient Population}

The study included adult patients with head injury and who were consulted in the emergency room (ER) between January and July of 2014. Computed tomography (CT) scans of 71 patients who had no pathological imaging findings were included in this study.

\section{Anatomical Definitions}

The distances from different midline convexity craniometric points, as nasion and bregma, to pre-central, central and postcentral sulci, were measured to determine its relationships on in-vivo samples.

The anatomical key points were defined as shown below:

- Nasion: Intersection point between frontal and nasal bones, located in a depressed area that connects the nasal bridge and the glabella.

- Bregma: Intersection point between frontal and sagittal sutures. It was first located in the upper axial planes of the skull, to accurately identify it in the sagittal plane. It appears as a hypodense line that interrupts the fullthickness continuity of the hyperdense bony signal.

- Central sulcus: Cortical invagination that shows an oblique disposition, and separates the frontal lobe from the parietal lobes. It was distinguished from others nearing sulci by its omega-shape disposition, evident in the upper axial cuts. The surrounding gyri (pre-central, post-central and subcentral) were also identified in order to confirm its patency, and to determine the followings landmarks. Its location was determined by the most medial convexity extension of the sulcus at the axial plane.
- Pre-central and post-central sulci. Cortical invaginations located in front and behind the central sulcus, respectively. They were identified in both axial and sagittal planes, as described above. In most cases, these sulci end in the lateral (sylvian) fissure. The location of the post-central sulcus was also determined by the most medial convexity extension of the sulcus at the axial plane; the pre-central sulcus was defined at the point where it intercepts the superior frontal sulcus (or its projection).

\section{Tomographic Data Acquisition and Image Processing}

The CT scanner used was Aquilion ONE 320 (Toshiba, Japan), with a multislice scanning acquisition protocol. Intravenous contrast administration was not required. The images were processed and analyzed by the software Alma Workstation V4.2.0.2 (Alma IT Systems).

\section{Statistical Analysis}

An observational retrospective cross-sectional study was made. All analyses were performed using the Statistical Package for the Social Sciences (SPSS for Windows version 19.0 SPSS Inc, Chicago, IL, USA). The Shapiro-Wilk test was used to test the normality assumption. Relative frequencies were calculated for categorical data. Continuous data was expressed as mean \pm standard deviation (SD). The twotailed independent sample t-test was performed to compare means between groups. $p$ values $<0.05$ were considered to be statistically significant.

\section{RESULTS}

Of the 71 patients, 38 (54\%) were female and 33 (46\%) were male (Table I). The mean age of the population was 56.9 years (36.4-77.4).

The mean distance between nasion and bregma ( $\mathrm{Na}-\mathrm{Br}$ ) was $137.4 \mathrm{~mm} \pm 7.8 \mathrm{~mm}$.

The mean distance from bregma to pre-central sulcus $(\mathrm{Br}$ preCS) was $26.8 \pm 7.2 \mathrm{~mm}$, to central sulcus (Br-CS) was 47.8 $\pm 5.9 \mathrm{~mm}$, and to post-central sulcus (Br-postCS) was $60.6 \pm$ $5.7 \mathrm{~mm}$ (Figure 1).

The mean distance from nasion to pre-central sulcus ( $\mathrm{Na}$ preCS) was $164.3 \pm 9.5 \mathrm{~mm}$, to central sulcus (Na-CS) was $185.2 \pm 9.6 \mathrm{~mm}$, and to post-central sulcus (Na-postCS) was $197.9 \pm 9.1 \mathrm{~mm}$.

The distance from central to pre-central (CS-preCS) and to post-central sulci (CS-postCS) was $20.9 \pm 5.9 \mathrm{~mm}$ and $12.7 \pm$ $4.5 \mathrm{~mm}$, respectively. The mean distance between pre-central and post-central sulci (preCS-postCS) was $33.7 \pm 6.2 \mathrm{~mm}$ (Table II).

There were significant differences in the measurements of nasion-bregma distances (Na-Br) among both sexes. The comparison between male and female showed a statistical significance when the measurement was related to the nasion (Na-preCS/CS/postCS), but was not when related to bregma (Br-preCS/CS/postCS). These results have been detailed in (Table III). 
Notably, taken on account the range of values obtained by measuring from the bregma to each sulcus, the most posterior positions of the central sulcus were in a dangerous proximity to the most anterior positions of the post-central sulcus (Figure 3A, B).

Table I: Descriptive Statistics of Categorical Variables

\begin{tabular}{cc}
\hline Variable & Relative Frequency $\mathbf{( 9 5 \% ~ C l )}$ \\
\hline Sex $(n=71)$ & \\
\hline Female & $54(42-65)$ \\
\hline Male & $46(35-58)$ \\
\hline
\end{tabular}

Cl: Confidence interval.

Table II: Descriptive Statistics of Continuous Variables for Total Sample $(n=71)$

\begin{tabular}{ll}
\hline Variable & Mean \pm SD \\
\hline Edad (years) & $56.9 \pm 20.5$ \\
\hline $\mathrm{Na}-\mathrm{Br}(\mathrm{mm})$ & $137.4 \pm 7.8$ \\
\hline Br-CS $(\mathrm{mm})$ & $47.8 \pm 5.9$ \\
\hline Br-pre CS $(\mathrm{mm})$ & $26.8 \pm 7.2$ \\
\hline Br-post CS $(\mathrm{mm})$ & $60.6 \pm 5.7$ \\
\hline Na-CS $(\mathrm{mm})$ & $185.2 \pm 9.6$ \\
\hline Na-pre CS $(\mathrm{mm})$ & $164.3 \pm 9.5$ \\
\hline Na-post CS $(\mathrm{mm})$ & $197.9 \pm 9.1$ \\
\hline pre CS $(\mathrm{mm})$ & $20.9 \pm 5.9$ \\
\hline post CS $(\mathrm{mm})$ & $12.7 \pm 4.5$ \\
\hline pre CS-post CS $(\mathrm{mm})$ & $33.7 \pm 6.2$ \\
\hline
\end{tabular}

SD: Standard deviation, Na: Nasion, Br: Bregma, CS: Central sulcus, pre CS: pre-central sulci, post CS: post-central sulci.

\section{Illustrative Case}

A sixty-four years old male without relevant clinical history was referred to the Neurosurgery Department following the diagnostic of meningioma. It was located in the brain convexity of the posterior right frontal lobe. The anterior region of the precentral gyrus was also distorted, due to tumoral mass effect (Figures 2A, B). The patient underwent resective surgery. After soft tissue detachment, the coronal and sagittal sutures, as well as bregma were easily found (Figure $2 \mathrm{C}$ ). The craniotomy was demarcated through craniometric relationships, without any guidance system. The middle frontal, superior frontal and pre-central gyri were preserved almost intact following Simpson grade I resection (Figure 2D). Despite transient mild right brachial paresis, the patient was discharged at the fifth postoperative day without neurological symptoms.

\section{DISCUSSION}

Although technologic advances offer modern intraoperative guidance tools such as intraoperative magnetic resonance image (MRI) and neuronavigation nowadays $(3,17,18)$, the anatomical knowledge remains an essential skill for neurosurgeons and trainees when planning and performing neurosurgical procedures, especially in situations in which those guidance systems are unsuitable or unavailable, such as emergency surgery (decompressive craniectomy, EVD and/or ICP monitor placement), or the initial management of complex neurotrauma in a military operational setting (11).

Although some articles have already measured these relations, most of them were performed on cadaveric specimens $(6-8,14,15)$. On the other hand, only a few articles described these relations by CT scans, and most of these were conducted in the pediatric population $(5,12,13)$, or using outdated methods $(4,9)$.

We performed our measurements on CT scans instead of cadaveric specimens, avoiding shifting of neuroanatomic

Table III: Univariate Analysis. Independent Sample T-Test

\begin{tabular}{lccc}
\hline \multirow{2}{*}{ Variable } & \multicolumn{2}{c}{ Sex } & \multirow{2}{*}{ p-value } \\
\cline { 2 - 3 } & Female $(\mathbf{n}=\mathbf{3 8})$ & Male $(\mathbf{n}=\mathbf{3 3})$ & $<0.001$ \\
\hline $\mathrm{Na}-\mathrm{Br}$ & $134.5 \pm 7.8$ & $140.7 \pm 6.5$ & $\mathrm{NS}$ \\
\hline Br-CS & $47.9 \pm 6.5$ & $47.6 \pm 5.2$ & $\mathrm{NS}$ \\
\hline Br-pre CS & $27.3 \pm 8.2$ & $26.3 \pm 5.9$ & $\mathrm{NS}$ \\
\hline Br-post CS & $61.1 \pm 5.9$ & $59.9 \pm 5.5$ & $<0.05$ \\
\hline Na-CS & $182.5 \pm 9.7$ & $188.3 \pm 8.5$ & $<0.05$ \\
\hline Na-pre CS & $161.9 \pm 8.9$ & $167.0 \pm 9.5$ & $<0.05$ \\
\hline Na-post CS & $195.6 \pm 9.1$ & $200.7 \pm 8.5$ & $\mathrm{NS}$ \\
\hline pre CS & $20.6 \pm 6.5$ & $21.3 \pm 5.1$ & $\mathrm{NS}$ \\
\hline post CS & $13.1 \pm 5.1$ & $12.3 \pm 3.7$ & $\mathrm{NS}$ \\
\hline pre CS-post CS & $33.7 \pm 6.7$ & $33.7 \pm 6.7$ & \\
\hline
\end{tabular}

p-value: two-sided p values for t-test. NS: not significant. Bold font indicates statistically significant results. Na: Nasion, Br: Bregma, CS: Central sulcus, pre CS: pre-central sulci, post CS: post-central sulci. 
structures due to cranial manipulation and brain tissue fixation. Also, the use of CT scans allowed reaching a larger sample size, securing more reliable results (4).

Both the mean distances Br-preCS and Br-CS found in this report are comprised in the wide range of mean values described on cadaveric-based works $(7,15,16)$, but are markedly similar with previous CT-based analyses (9). This empirical observation reinforces the CT scan as a reliable source of data.

As demonstrated, there was a significant statistical difference $(\mathrm{p}<0.05)$ in the $\mathrm{Na}-\mathrm{Br}$ distance between males and females. However, the mean distances from bregma to the brain sulci were more constant among sexes. Therefore, we recommend the use of bregma instead of nasion or glabella, in order to avoid gender variations.

Transferring this data into the operating room, the safest way to recognize the central lobe is to initially identify the pre- central sulcus, and then the posterior sulci, because the gap of the posterior and anterior extreme values between the precentral and central sulci, respectively, were wider.

\section{CONCLUSION}

The most accurate craniometric relationship to determine the location of the central lobe gyri has been found to be related to the bregma. Regarding the central sulcus, it was located on average $4.78 \mathrm{~mm}$ behind the bregma. These results offer safe and suitable data for guiding neurosurgical procedures and for the implementation of technological guidance systems, if available.

\section{REFERENCES}

1. Campero A, Ajler P, Emmerich J, Goldschmidt E, Martins C, Rhoton A: Brain sulci and gyri: A practical anatomical review. J Clin Neurosci 21:2219-2225, 2014
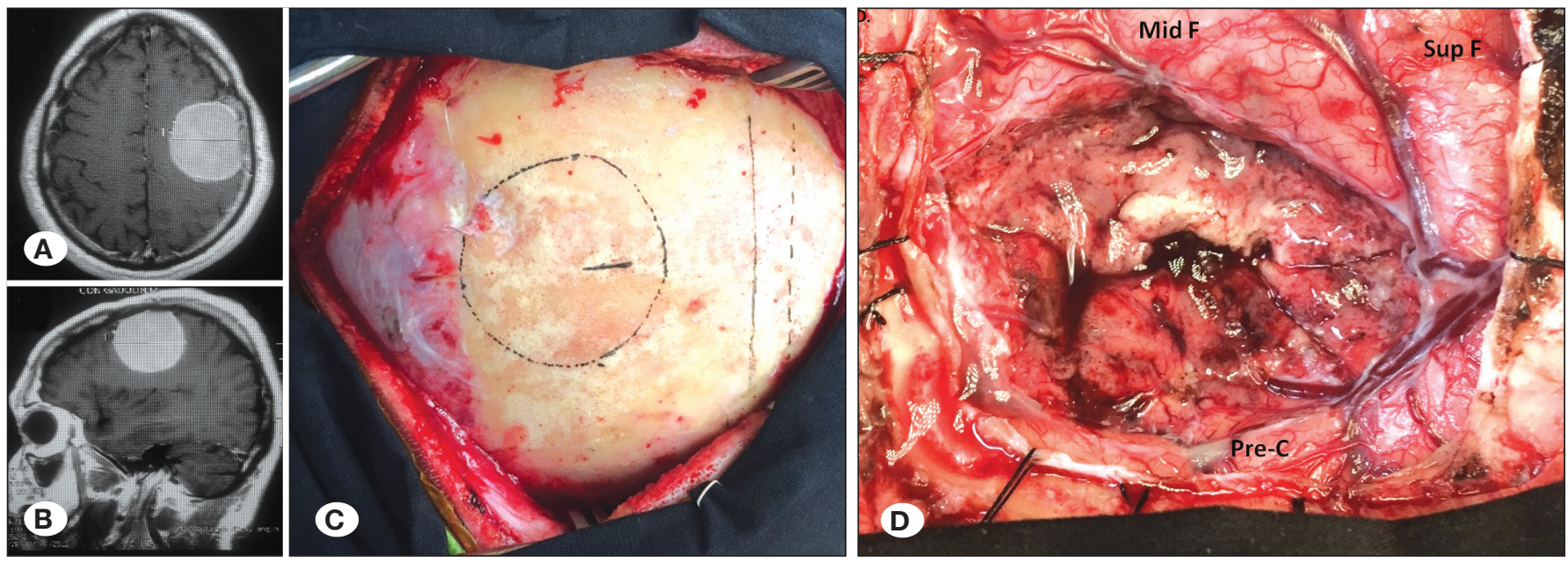

Figure 2: Case illustration. A, B) Axial and sagittal MRI slices showing a well delimited, highly contrast-enhanced, expansive frontal brain tumor. As can be inferred by the contralateral central sulcus "omega sign", the anterior aspect of the central lobe (pre-central sulcus and gyrus) was mainly affected. C) Intraoperative image. Tumor projection on the skull related to the coronal and sagittal cranial sutures (intermittent line: sagittal suture; continue line: medial craniotomy border; dotted line: tumor boundaries). D) Surgical bed. Middle frontal (Mid F), superior frontal (Sup F) and pre-central (Pre-C) gyri following total resection.
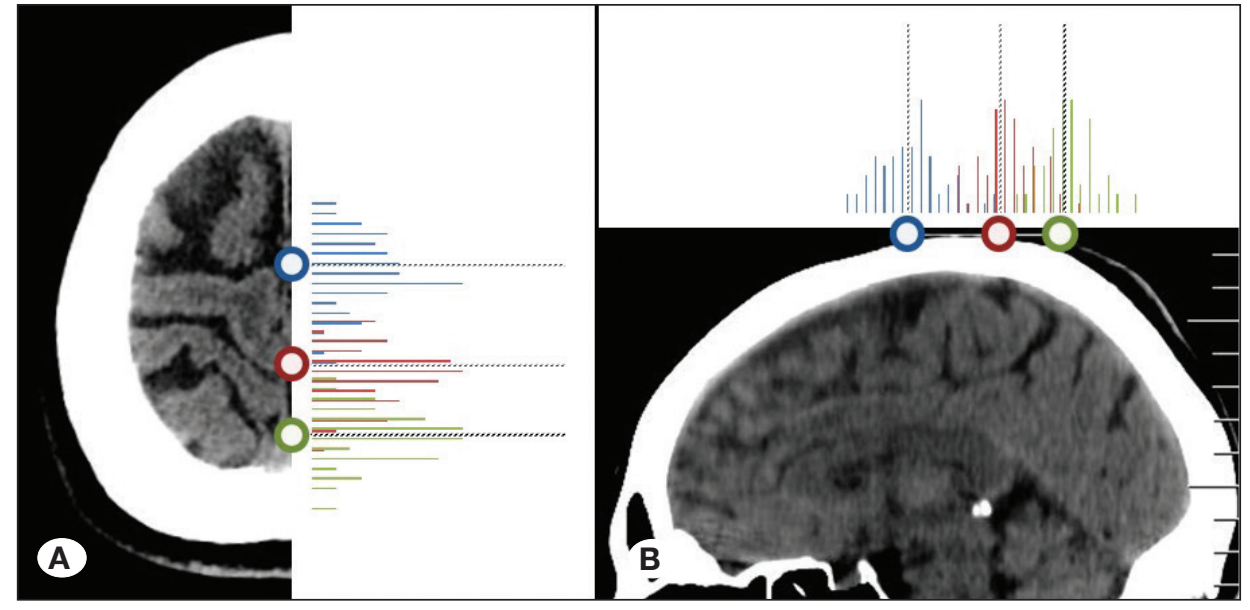

Figure 3: Axial (A) and sagittal (B) tomographic slices summarizing frequency distributions (continuous bar) and mean value (interrupted bar) of the distance from bregma to each central lobe sulci (circle).

Blue: precentral sulcus; red: central sulcus, green: post-central sulcus. 
2. Campero A, Ajler P, Martins C, Emmerich J, de Alencastro LF, Rhoton A Jr: Usefulness of the contralateral Omega sign for the topographic location of lesions in and around the central sulcus. Surg Neurol Int 2:164, 2011

3. Coenen VA, Krings $T$, Axer $H$, Weidemann J, Kränzlein $H$, Hans FJ, Thron A, Gilsbach JM, Rohde V: Intraoperative three-dimensional visualization of the pyramidal tract in a neuronavigation system (PTV) reliably predicts true position of principal motor pathways. Surg Neurol 60:381-390, 2003

4. Ebeling $U$, Huber P, Reulen HJ: Localization of the precentral gyrus in the computed tomogram and its clinical application. J Neurol 233:73-76, 1986

5. Furuya Y, Edwards MS, Alpers CE, Tress BM, Ousterhout DK, Norman D: Computerized tomography of cranial sutures. Part 1: Comparison of suture anatomy in children and adults. J Neurosurg 61:53-58, 1984

6. Gonzales-Portillo G: Localization of the central sulcus. Surg Neurol 46:97-99, 1996

7. Gusmão S, Reis C, Silveira RL, Cabral G: Relationships between the coronal suture and the sulci of the lateral convexity of the frontal lobe: Neurosurgical applications. Arq Neuropsiquiatr 59:570-576, 2001

8. Gusmão S, Silveira RL, Arantes A: Landmarks to the cranial approaches. Arq Neuropsiquiatr 61:305-308, 2003

9. Kido DK, LeMay M, Levinson AW, Benson WE: Computed tomographic localization of the precentral gyrus. Radiology 135:373-377, 1980

10. Korvenoja A, Kirveskari E, Aronen HJ, Avikainen S, Brander $A$, Huttunen J, Ilmoniemi RJ, Jääskeläinen JE, Kovala $T$, Mäkelä JP, Salli E, Seppä M: Sensorimotor cortex localization: Comparison of magnetoencephalography, functional MR imaging, and intraoperative cortical mapping. Radiology 241:213-222, 2006
11. Mauer UM, Kunz U: Management of neurotrauma by surgeons and orthopedists in a military operational setting. Neurosurg Focus 28:E10, 2010

12. Mitchell LA, Kitley CA, Armitage TL, Krasnokutsky MV, Rooks VJ: Normal sagittal and coronal suture widths by using CT imaging. AJNR Am J Neuroradiol 32:1801-1805, 2011

13. Regelsberger J, Schmidt T, Busse B, Herzen J, Tsokos $M$, Amling $M$, Beckmann F: Synchrotron-microcomputed tomography studies of normal and pathological cranial sutures: Further insight. J Neurosurg Pediatr 5:238-242, 2010

14. Ribas GC, Yasuda A, Ribas EC, Nishikuni K, Rodrigues AJ Jr: Surgical anatomy of microneurosurgical sulcal key points. Neurosurgery 59:ONS177-210; discussion ONS210-1, 2006

15. Sarmento SA, Jácome DC, de Andrade EMF, Melo AVA, de Oliveira OR, Tedeschi H: Relationship between the coronal suture and the central lobe: How important is it and how can we use it in surgical planning? Arq Neuropsiquiatr 66:868871,2008

16. Weber J, Collmann H, Czarnetzki A, Spring A, Pusch CM: Morphometric analysis of untreated adult skulls in syndromic and nonsyndromic craniosynostosis. Neurosurg Rev 31:179188, 2008

17. Wilkinson ID, Romanowski CAJ, Jellinek DA, Morris J, Griffiths PD: Motor functional MRI for pre-operative and intraoperative neurosurgical guidance. Br J Radiol 76:98-103, 2003

18. Zimmermann M, Seifert V, Trantakis C, Raabe A: Open MRI-guided microsurgery of intracranial tumours in or near eloquent brain areas. Acta Neurochir 143:327-337, 2001 